\title{
Red-emitting alkaline-earth rare-earth pentaoxometallates powders prepared by metal carboxylates solution
}

\author{
KYU-SEOG HWANG, SUNG-DAE KIM, SEUNG HWANGBO ${ }^{\dagger}$ and JIN-TAE KIM ${ }^{\dagger \dagger}$, * \\ Department of Biomedical Engineering, Nambu University, 864-1 Wolgye-dong, Gwangsan-gu, Gwangju 506824, Korea \\ $\dagger$ Department of Electronic and Photonic Engineering, Honam University, 59-1 Seobong-dong, Gwangsan-gu, \\ Gwangju 506714, Korea \\ $\dagger$ Department of Photonic Engineering, Chosun University, 375 Seosuk-dong, Dong-gu, Gwangju 501759, Korea
}

MS received 1 February 2012; revised 10 April 2012

\begin{abstract}
Moisture-insensitive metal carboxylates that are mostly liquids at room temperature have been first applied to the preparation of strontium europium aluminate $\left(\mathrm{Sr}_{2} \mathrm{EuAlO}_{5}\right)$ powders for red-emitting phosphor under near ultraviolet radiation. Strontium naphthenate, aluminium-2-ethylhexanoate and europium-2-ethylhexanoate were dissolved with toluene to prepare starting solution. Precursor pyrolyzed at $500{ }^{\circ} \mathrm{C}$ for 240 min was finally annealed at $900-1200{ }^{\circ} \mathrm{C}$ for $240 \mathrm{~min}$ in Ar. X-ray diffraction analysis, field emission-scanning electron microscope and fluorescent spectrophotometer were used to evaluate structural and optical properties. For the $1000{ }^{\circ} \mathrm{C}$-annealed powders with regular shape and narrow size distribution confirmed by FE-SEM observation, strong red emission at $615 \mathrm{~nm}$ under the excitation of $395 \mathrm{~nm}$ maximum was reached, then the higher annealed samples at above $1100{ }^{\circ} \mathrm{C}$ gave the lower emission intensities.
\end{abstract}

Keywords. Metal carboxylates; $\mathrm{Sr}_{2} \mathrm{EuAlO}_{5}$; Phosphor.

\section{Introduction}

In recent years, research into tricolour phosphors suitable for near ultraviolet (UV) light emitting diode (LED) has attracted increasing attention, because of these significant applications in solid-state lighting (Hwang et al 2009; Qiang et al 2009). The emission of Eu ion is highly efficient and its emission wavelength is strongly dependent on the host lattice so that previous works can get different colour from blue to red in theory (Liu et al 2005). The luminescence of $\mathrm{Eu}^{3+}$, in the case of a non-centrosymmetric environment, is generally dominated by the ${ }^{5} D_{0} \rightarrow{ }^{7} F_{2}$ transition yielding a redemitting phosphor suitable for lamps and displays (Song et al 2008).

The conventional routine to synthesize the commercial phosphors is based on a high temperature solid-state reaction method. Although various improved wet-chemical methods have been used to overcome drawbacks of solid-state reaction, the properties of phosphors appear to be strongly depend on the processing conditions and starting materials (Escribano et al 2005; Jia et al 2007). Since expensive metal alkoxides commonly used in wet-chemical method are very much unstable in air and demand a complicated procedure, its commercial applicability for powder synthesis is limited. Among the various starting materials for wetchemical methods, metal carboxylates complex are potential precursors for the formation of oxides at low temperature.

\footnotetext{
*Author for correspondence (kimjt@ mail.chosun.ac.kr)
}

Metal carboxylates such as, metal naphthenates and metal 2-ethylhexanoates are more advantageous than metal alkoxides in terms of stability in air and ease of handling (Narendar and Messing 1997; Walker Jr et al 1998). Furthermore, metal carboxylates have potential for oxide powder synthesis because the metal cations are molecularly mixed in the precursor, and as a result phase-pure multicomponent oxides can form at low temperature.

Strontium aluminate $\left(\mathrm{SrAl}_{2} \mathrm{O}_{4}\right)$ is one of the most promising host materials for long lasting phosphor (LLP) (Zhang et al 2009; Shafia et al 2010). Among the various strontium aluminate phosphors, it is well known that $\mathrm{Eu}^{2+}$ ionsdoped $\mathrm{SrAl}_{2} \mathrm{O}_{4}$ phosphor for green emitting has been found extensive applications as LLP (Zhang et al 2009; Shafia et al 2010). However, luminescence property of $\mathrm{Eu}^{3+}$ in red-emitting $\mathrm{Sr}_{2} \mathrm{EuAlO}_{5}$ has seldom been reported. After the structure of alkaline-earth rare-earth pentaoxometallates, such as $\mathrm{Sr}_{2} R e \mathrm{eFe}_{5}$ and $\mathrm{Sr}_{2} R e \mathrm{AlO}_{5}(R e=\mathrm{Pr}, \mathrm{Nd}, \mathrm{Sm}, \mathrm{Eu}$, and Gd) were investigated by Drofenik and Goli (1979), no attempt has been made to optimize the experimental procedures or to evaluate luminescence property, except for previous work (Hempel 2007) on crystal structure and luminescence properties for blue-emitting $\mathrm{Sr}_{2} \mathrm{EuAlO}_{5}$. Since the coordination environment of the two strontium sites in these compounds are noticeably different, it is possible that cation ordering can be induced by replacing strontium with another alkaline-earth ion, or possibly even a rare-earth ion and alkali metal cation pair. The site preferences of substitutional ions and the corresponding structural distortions that accompany these substitutions have implications for the preparation of 
new optical materials. To the best of our knowledge, so far no paper has been published on the preparation of red-emitting $\mathrm{Sr}_{2} \mathrm{EuAlO}_{5}$ phosphors by using metal carboxylates complex.

In this work, we prepared red-emitting $\mathrm{Sr}_{2} \mathrm{EuAlO}_{5}$ nanopowders under the $395 \mathrm{~nm}$ irradiation by an aqueous chemical method. The effect of processing temperature on the formation of host phase structure and subsequently on the photoluminescence was examined.

\section{Experimental}

Stoichiometric mixture of strontium naphthenate $\left(\mathrm{Sr} \cdot 2\left(\mathrm{C}_{11} \mathrm{H}_{7} \mathrm{O}_{2}\right)\right)$, europium(III) 2-ethylhexanoate $\left(\mathrm{Eu}\left(\mathrm{C}_{8} \mathrm{H}_{15} \mathrm{O}_{2}\right)_{3}\right)$ and hydroxyaluminum bis(2-ethylhexanoate) $\left(\mathrm{C}_{16} \mathrm{H}_{31} \mathrm{AlO}_{5}\right)$ were used as starting materials and toluene was used as a solvent. Starting materials were

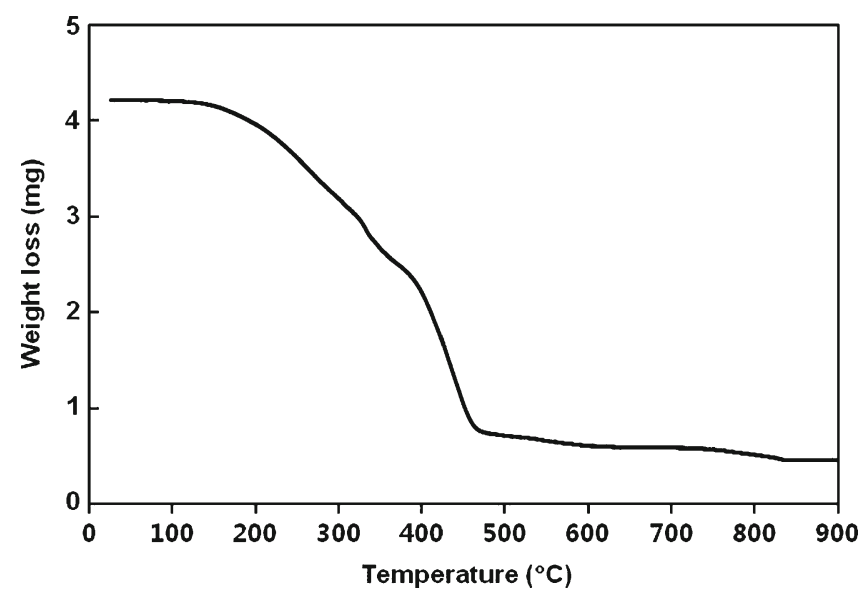

Figure 1. TGA curve of starting solution used in this work. dissolved with toluene at $60{ }^{\circ} \mathrm{C}$ for $24 \mathrm{~h}$ in air. The homogeneous solution was converted to yellowish powder by pre-firing at $500{ }^{\circ} \mathrm{C}$ for $4 \mathrm{~h}$ in air, and then the precursor was finally annealed at $900-1200{ }^{\circ} \mathrm{C}$ for $4 \mathrm{~h}$ in Ar.

Thermogravimetry analysis (TGA, DTG-60, Shimadzu, Japan) was used to analyse the thermal decomposition behaviour of the precursor solution with a heating rate of $3{ }^{\circ} \mathrm{C} / \mathrm{min}$ in $\mathrm{Ar}$ up to $800^{\circ} \mathrm{C}$. X-ray diffraction profiles were measured using a X-ray diffractometer (XRD, D-Max-1200, Rigaku, Japan), equipped with a $\mathrm{CuK} \alpha$ radiation source and a graphite monochrometer. Particle size and shapes were observed by field emission-scanning electron microscope (FE-SEM, S-4700, Hitachi, Japan). The excitation and emission spectra of the powders were recorded on a fluorescent spectrophotometer (Darsapro-5000 system, PSI, Republic of Korea).

\section{Results and discussion}

The pyrolysis behaviour of the obtained solution is studied by TGA as shown in figure 1 . The first stage from room temperature to $300{ }^{\circ} \mathrm{C}$ seems to be related to the evaporation of volatile residues, mainly toluene, probably. The final stage is associated with further decomposition and combustion of the organics. Over $500{ }^{\circ} \mathrm{C}$, the mass stays nearly constant. It can be seen that most of the mass loss occurs below $500{ }^{\circ} \mathrm{C}$, and the mass loss is about $87 \mathrm{wt} \%$, which is mainly due to the evaporation of the solvent and the decomposition of the organic complex compound.

The XRD spectra of the powders finally annealed at different temperatures are shown in figure 2. For the sample annealed at $900{ }^{\circ} \mathrm{C}$, all diffraction peaks can be readily indexed to tetragonal $\mathrm{Sr}_{2} \mathrm{EuAlO}_{5}$ (JCPDS Card No. 702197). However, the wide and weak diffraction peaks are

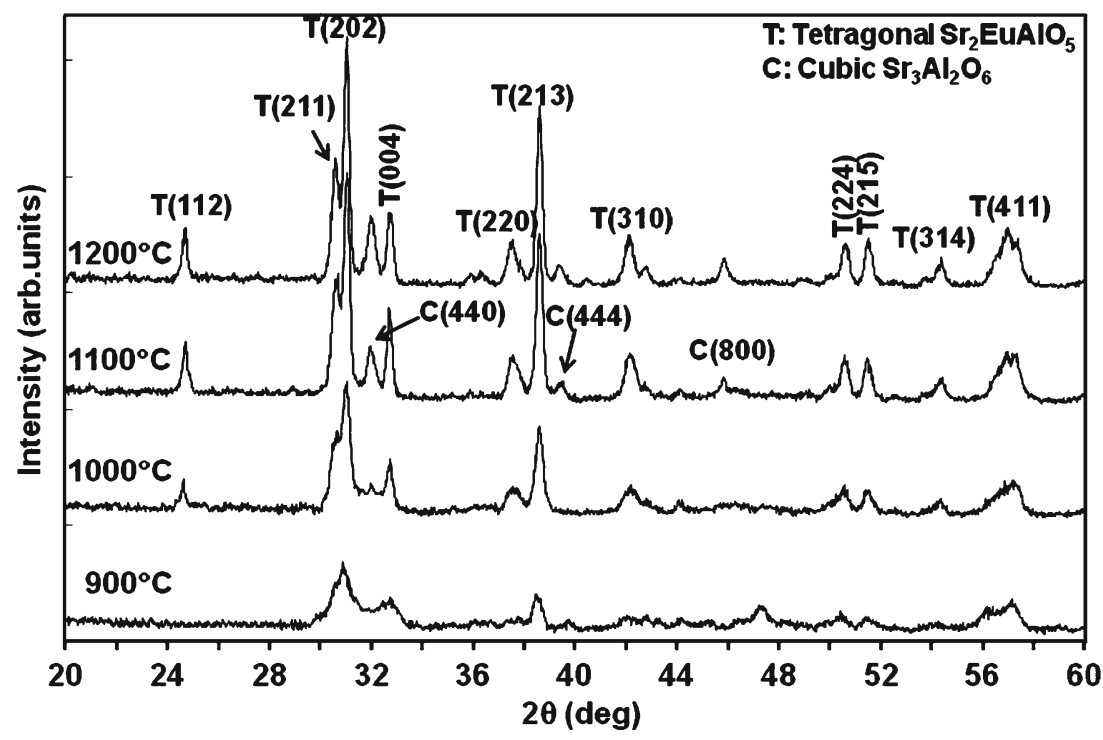

Figure 2. XRD patterns of powder after annealing at $900-1200{ }^{\circ} \mathrm{C}$. 
indicative of the poor crystallinity as well as fine grain size of the synthesized sample at $900{ }^{\circ} \mathrm{C}$. Annealing at $1000{ }^{\circ} \mathrm{C}$ gives well-crystallized powder although probably with some traces of the second cubic $\mathrm{Sr}_{3} \mathrm{Al}_{2} \mathrm{O}_{6}$ (JCPDS Card No. 81$0506)$ at $2 \theta=31.9-32^{\circ}$ owing to (440) reflection. When the annealing temperature is further raised to 1100 and $1200{ }^{\circ} \mathrm{C}$, the width of the diffraction peaks becomes narrow, resulting in the particle size increase and crystallization improves with increasing temperature. However, with an increase in the annealing temperature, some characteristic peaks corresponding to additional cubic $\mathrm{Sr}_{3} \mathrm{Al}_{2} \mathrm{O}_{6}$ phase are increased in the patterns for the samples annealed at 1100 and $1200{ }^{\circ} \mathrm{C}$.

Crystal of $\mathrm{Sr}_{2} \mathrm{EuAlO}_{5}$ is tetragonal, space group $14 / \mathrm{mcm}$. The structure $\mathrm{Sr}_{2} \mathrm{EuAlO}_{5}$, which is isotypic with the $\mathrm{Cs}_{3} \mathrm{CoCl}_{5}$ structure, contains isolated $\mathrm{AlO}_{4}$ tetrahedra arranged about the (001) plane. The unit cell contains eight $\mathrm{Sr}$, four $\mathrm{Eu}$, four $\mathrm{Al}$ and twenty $\mathrm{O}$ atoms. The tetrahedra are angularly distorted with two O-Al-O angles of $99.4^{\circ}$ and four of $114.7^{\circ}$, which causes distortion from tetrahedral symmetry of the $\mathrm{O}$ atom arrangement around $\mathrm{Al}$. The $\mathrm{O}$ atom which is not a part of the tetrahedron is octahedrally coordinated by $\mathrm{Sr}$ and $\mathrm{Eu}$ (Drofenik and Goli 1979). Using XRD peaks, the $a$ - and $c$ - and $a_{0}$-lattice spacings for the tetragonal $\mathrm{Sr}_{2} \mathrm{EuAlO}_{5}$ and the cubic $\mathrm{Sr}_{3} \mathrm{Al}_{2} \mathrm{O}_{6}$ were observed to be $0.677-6.802 \mathrm{~nm}, 1.093-1.095 \mathrm{~nm}$ and $1.580-1.583 \mathrm{~nm}$, respectively. These values are similar to the reference value of $a=0.6742 \mathrm{~nm}$ and $c=1.0970 \mathrm{~nm}$ for the tetragonal $\mathrm{Sr}_{2} \mathrm{EuAlO}_{5}$ and $a_{0}=1.586 \mathrm{~nm}$ for the cubic $\mathrm{Sr}_{3} \mathrm{Al}_{2} \mathrm{O}_{6}$.

The morphology and particle size exhibit deep effect on phosphor's luminescent properties when it is coated on a LED chip, thus the FE-SEM micrographs of the phosphors are investigated. Figure 3 shows the FE-SEM micrographs of the powder after annealing at various temperatures, which reveals the change in morphology and grain size of the powder based on the different annealing temperature. It can be seen from figure 3(a) that the particles after annealing at $900{ }^{\circ} \mathrm{C}$ are very fine. With an increase in the annealing temperatures, the particles of the powders start to bond together and the sizes enlarge obviously. At the early stage in annealing, the neck and the stomata among the particles are filled with materials, while the bonding of particles becomes more evident and the grain grows with the increase in annealing temperature at the late stage. When the annealing temperature reached $1000{ }^{\circ} \mathrm{C}$ as shown in figure $3(\mathrm{~b})$, the particle size of the powders increased to above $100 \mathrm{~nm}$ and their shape became nearly spherical. Figure 3(c and d) shows the FE-SEM micrographs of the powders annealed at 1100 and $1200{ }^{\circ} \mathrm{C}$, and the particle shows heavy agglomerate, wide size distribution and irregular shape. Our experimental results indicate that the powders with regular shape and narrow size distribution can be obtained by annealing at $1000^{\circ} \mathrm{C}$.
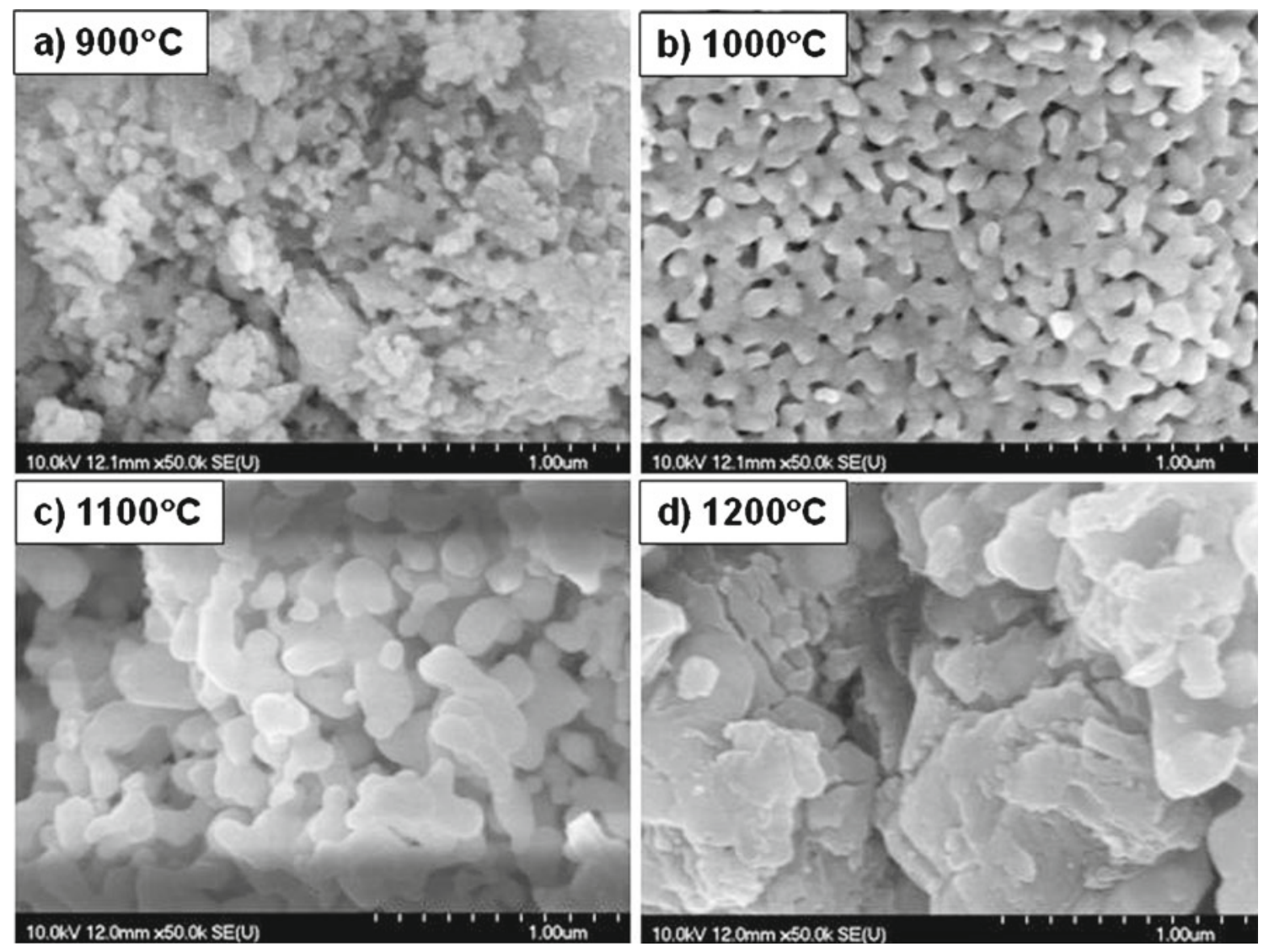

Figure 3. FE-SEM images of powder after annealing at $900-1200{ }^{\circ} \mathrm{C}$. 
Figure 4(a and b) shows the excitation and the emission spectra of powders after annealing at different temperatures. Their excitation and emission spectra are similar in the shapes and locations excluding relative intensities. The excitation spectra of the emission at $615 \mathrm{~nm}$ for ${ }^{5} D_{0} \rightarrow{ }^{7} F_{2}$ transition of the powders after annealing are illustrated in figure 4(a). It can be seen clearly that the excitation spectra are composed of a group of sharp lines in the $350 \sim 500 \mathrm{~nm}$ wavelength range. The lines in above region are assigned to the intraconfigurational $4 f-4 f$ forbidden transitions of $\mathrm{Eu}^{3+}$ in the host lattice: ${ }^{7} F_{0} \rightarrow{ }^{5} D_{4},{ }^{7} F_{1} \rightarrow{ }^{5} L_{6},{ }^{7} F_{0} \rightarrow{ }^{5} D_{3}$ and ${ }^{7} F_{0} \rightarrow{ }^{5} D_{2}$ at wavelengths $360,395,415$ and $465 \mathrm{~nm}$, respectively. The strongest excitation line at $395 \mathrm{~nm}$ contributes to the ${ }^{7} F_{1} \rightarrow{ }^{5} L_{6}$ transition in the near-UV region, which makes it possible for the phosphors to apply with near-UV LED.

Because the purpose of present work is on the near-UV GaN-based LED phosphor, only the spectroscopic properties in the range of $350-400 \mathrm{~nm}$ are concerned. The emission spectra for the samples after annealing at various temperatures under the excitation of $395 \mathrm{~nm}$ near UV light are shown in figure 4(b). It can be seen that the emission intensity increases with an increase in annealing temperature at $1000{ }^{\circ} \mathrm{C}$. The crystallinity of powder improves and regular-shaped crystal grains grow as annealing temperature increases to $1000{ }^{\circ} \mathrm{C}$, as shown in figures 2 and 3 . The improved crystallinity and homogeneous distribution of Eu ions in lattice result in the increase of emission intensity. It can be seen that the powder annealed at $1000{ }^{\circ} \mathrm{C}$ exhibits higher excitation and emission intensities indicating a high concentration of trivalent state than those annealed at higher temperature, 1100 and $1200{ }^{\circ} \mathrm{C}$ (shown in figure $4(\mathrm{a}$ and $\mathrm{b})$ ).

All spectra after annealing at various temperatures show the $f-f$ transition bands of Eu(III), which correspond to the emission from ${ }^{5} D_{0}$ level to the ground state ${ }^{7} F_{j}(j=0,1,2$ and 3). No remarkable difference is found in their emission spectra excluding their relative intensities under the excitation of $395 \mathrm{~nm}$. The strong red emission at about $615 \mathrm{~nm}$ ascribes to the ${ }^{5} D_{0} \rightarrow{ }^{7} F_{2}$ transition. The weak orange emission at around $590 \mathrm{~nm}$ belongs to ${ }^{5} D_{0} \rightarrow{ }^{7} F_{1}$ transition. Other emission peaks are located at 655 and $702 \mathrm{~nm}$, attributed to the transition from ${ }^{5} D_{0} \rightarrow{ }^{7} F_{3}$ and ${ }^{5} D_{0} \rightarrow{ }^{7} F_{4}$ levels, respectively.

PL intensities (defined as the integrated area intensities of all PL peaks) of the $\mathrm{Eu}^{3+}$ in $\mathrm{Sr}_{2} \mathrm{EuAlO}_{5}$ were highly affected by final annealing temperature. Figure 5(a) shows the emission intensities at 590 and $615 \mathrm{~nm}$ under $395 \mathrm{~nm}$ irradiation as a function of the annealing temperature. Emission brightness was highly enhanced with increasing annealing temperature and then reached maximum as the temperature increase up to above $1000{ }^{\circ} \mathrm{C}$. This is because the crystallinity of $\mathrm{Sr}_{2} \mathrm{EuAlO}_{5}$ powder increases with increasing annealing temperature from 900 to $1000{ }^{\circ} \mathrm{C}$, as shown in figure 2. However, as shown in figure 5(a), higher the annealing temperature at above $1100{ }^{\circ} \mathrm{C}$, lower the emission intensities. Generally, high annealing temperature could reduce quenching centres, thereby improving the emission intensity, while the crystal structure prepared at lower temperature was fairly disordered and quenching centres were present in relatively larger quantities, leading to weakened emission (Hong et al 2001). The reason for our work may be that the luminescence intensity of powder depends strongly on the particle shape, size distribution and impurity phase. A narrow size distribution and regular shape are necessary for the phosphor with proper emission characteristics. The powder annealed at $1000{ }^{\circ} \mathrm{C}$ have a narrow particle size distribution and homogeneous shape, as shown in figure 3, which are favourable to phosphor applied for LED
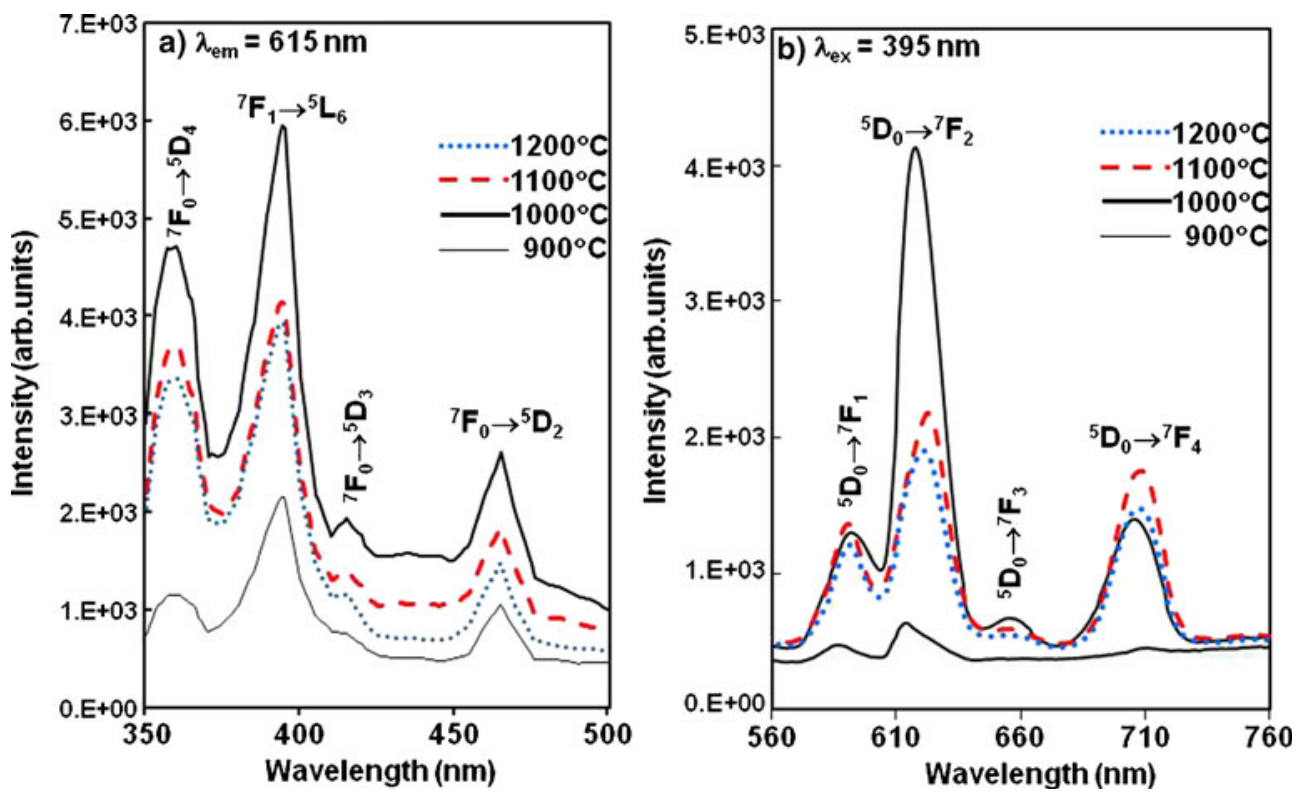

Figure 4. Excitation (a) and emission (b) spectra of powder after annealing at $900-1200{ }^{\circ} \mathrm{C}$. 

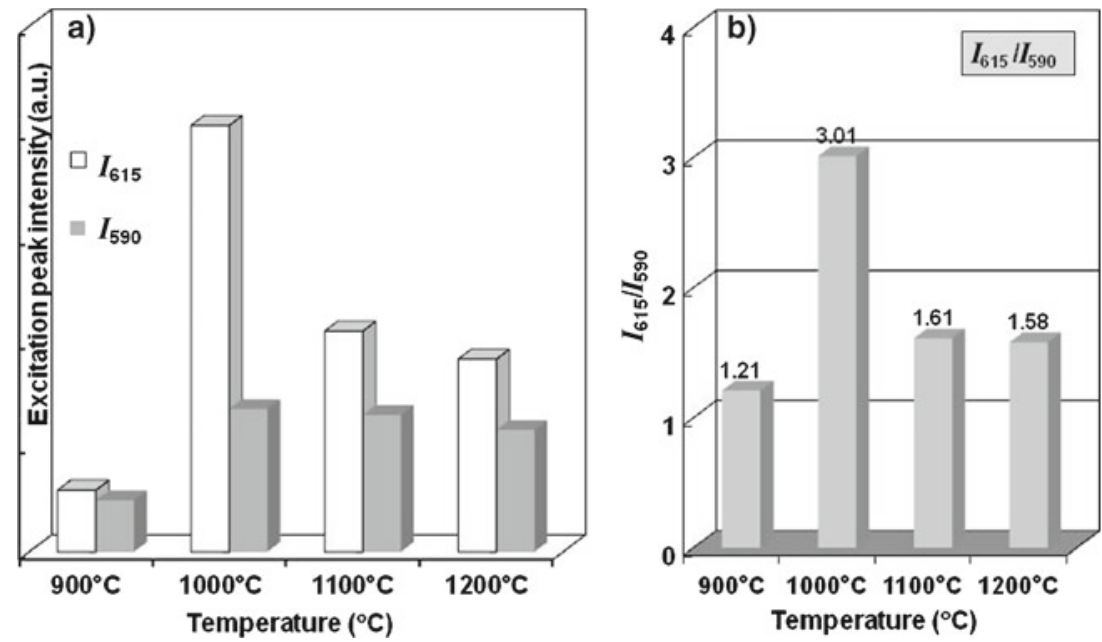

Figure 5. Emission intensities at 615 and $590 \mathrm{~nm}$ (a) and ratio of $I_{615} / I_{590}$ (b), as a function of annealing temperature.

because of less contamination or fewer dead layers, compared with the powders annealed at 1100 and $1200{ }^{\circ} \mathrm{C}$. Furthermore, the XRD peaks of the powder annealed at 1100 and $1200{ }^{\circ} \mathrm{C}$ indicate that the additional phase is also formed. Generally, with the increase of the annealing temperature, the doping rare-earth element could easily transfer into the lattice of the matrix, which results in the enhancement of the fluorescence intensity. In this work, however, annealed temperature higher than $1000{ }^{\circ} \mathrm{C}$ will lead to a remarkable decrease in fluorescence intensity. The diffraction patterns of the samples annealed at 1100 and $1200{ }^{\circ} \mathrm{C}$ show that the peaks are due to the tetragonal $\mathrm{Sr}_{2} \mathrm{EuAlO}_{5}$ phase and the cubic $\mathrm{Sr}_{3} \mathrm{Al}_{2} \mathrm{O}_{6}$ phase could be clearly detected. The decrease of emission intensity at above $1100{ }^{\circ} \mathrm{C}$ is inversely proportional to the enhancement of the additional cubic phase, which may be caused by the increasing defects during the morphology changes, although further research will be done for the effect of additional cubic $\mathrm{Sr}_{3} \mathrm{Al}_{2} \mathrm{O}_{6}$ phase on the crystal structure of tetragonal $\mathrm{Sr}_{2} \mathrm{EuAlO}_{5}$.

Figure 5(b) shows the variation of the ratio of the emission intensities at $615 \mathrm{~nm}$ to that at $590 \mathrm{~nm}\left(I_{615} / I_{590}\right)$ as a function of annealing temperature. The ratio between the areas of the 'hypersensitive' electronic ${ }^{5} D_{0} \rightarrow{ }^{7} F_{2}$ and the magnetic dipolar ${ }^{5} D_{0} \rightarrow{ }^{7} F_{2}$ transitions, which is considered as a parameter to measure the asymmetry in the vicinity of $\mathrm{Eu}^{3+}$ ions and $\mathrm{Eu}-\mathrm{O}$ covalence. It has been established that this ratio increases when the lattice environment is distorted due to the odd parity crystal field parameters (Nogami et al 2002; Qiang et al 2009). It can be found that the $I_{615} / I_{590}$ value highly increases with the increase of annealing temperature up to $1000{ }^{\circ} \mathrm{C}$. The increase of ratio $\left(I_{615} / I_{590}\right)$ indicates that the probability of electron dipole transition increases with the increase of annealing temperature. This proves that annealing temperature at $1000{ }^{\circ} \mathrm{C}$ changes the local environment of $\mathrm{Eu}^{3+}$ ions (Cordoncillo et al 2009; Qiang et al 2009).
$\mathrm{Sr}_{2} \mathrm{EuAlO}_{5}$ sample annealed at $1000{ }^{\circ} \mathrm{C}$ and higher, does not exhibit long-lasting luminescence under $395 \mathrm{~nm}$ irradiation. These results indicate that some kind of defects are required inside the network in order to favour the electronhole recombination. A more accurate analysis of the optical properties is then performed.

Previously, the rare-earth ion-doped $\mathrm{SrAl}_{2} \mathrm{O}_{4}$ phosphor system was prepared by a solid-state reaction running to several hours/days at a very high temperature $\left(\sim 1900^{\circ} \mathrm{C}\right)$ (Pet et al 1989). This is a serious limitation for the production of this phosphor on an industrial scale. Furthermore, several new chemical methods by using metal alkoxides and inorganic salts require a high degree of sophistication and control of the various parameters involved in the preparation, thereby introducing limitations on up-scaling the synthesis for commercial applications. In this work, a simple wetchemical process using metal carboxylates and toluene as the solvent was first adopted to fabricate nano-sized red-emitting $\mathrm{Sr}_{2} \mathrm{EuAlO}_{5}$. Since metal carboxylates are used as the starting materials, the problems of handling moisture-sensitive alkoxides and the complicated processes, such as hydrolysis and polycondensation, can be avoided, although further research on the removal of unwanted crystalline for improving their photoluminescence properties will be done.

\section{Conclusions}

The $\mathrm{Sr}_{2} \mathrm{EuAlO}_{5}$ nanoparticles could be obtained by wetchemical process by using metal carboxylates as starting materials. Annealing temperature from 900 to $1200{ }^{\circ} \mathrm{C}$ leads to an increase of diffraction peak intensities. Some characteristic peaks corresponding to additional $\mathrm{Sr}_{3} \mathrm{Al}_{2} \mathrm{O}_{6}$ phase are indexed and increased for the powders annealed at above $1100{ }^{\circ} \mathrm{C}$. All spectra after annealing at various temperatures show the $f-f$ transition bands of $\mathrm{Eu}(\mathrm{III})$, which correspond 
to the emission from ${ }^{5} D_{0}$ level to the ground state ${ }^{7} F_{j}(j=0$, 1,2 and 3). For the $1000{ }^{\circ} \mathrm{C}$-annealed powders with regular shape and narrow size distribution confirmed by FESEM observation, strong red emission at $615 \mathrm{~nm}$ under the excitation of $395 \mathrm{~nm}$ was reached maximum, then the higher annealed samples at above $1100{ }^{\circ} \mathrm{C}$ gave the lower emission intensities. The results indicate that $\mathrm{Sr}_{2} \mathrm{EuAlO}_{5}$ nanopowder annealed at $1000{ }^{\circ} \mathrm{C}$ is a promising candidate red phosphor applied in near UV-LEDs.

\section{References}

Cordoncillo E, Julian-Lopez B, Martínez M and Sanjuán M L 2009 J. Alloys Compd. 484693

Drofenik M and Goli L 1979 Acta Crystallogr. B35 1059

Escribano P, Marchal M, Sanjuán M L, Alonso-Gutiérrez P, Julián B and Cordoncillo E 2005 J. Solid State Chem. 1781978

Hempel W 2007 Dissertation zur Erlangung des Doktorgrads Universität Augsburg
Hong G, Jeon B, Yoo Y and Yoo J 2001 J. Electrochem. Soc. 148 H161

Hwang K S, Hwangbo S and Kim J T 2009 Ceram. Int. 352517

Jia D, Wang Y, Guo X, Li K, Zou Y K and Jia W 2007 J. Electrochem. Soc. $154 \mathrm{~J} 1$

Liu B, Shi C, Yin M, Dong L and Xiao Z 2005 J. Alloys Compd. 38765

Narendar Y and Messing G L 1997 J. Am. Ceram. Soc. 80915

Nogami M, Enomoto T and Hayakawa T 2002 J. Lumin. 97147

Pet R J, Van der Nienwenhof M and Duisters J P H M 1989 US Patent 4795588

Qiang R F, Xiao S, Ding J W, Yuan W and Zhu C 2009 J. Lumin. 129826

Shafia E, Bodaghi M and Tahriri M 2010 Curr. Appl. Phys. 10 596

Song F, Donghua C and Yuan Y 2008 J. Alloys Compd. 458 564

Walker Jr E H, Breen M L and Apblett A W 1998 Chem. Mater. 101265

Zhang R, Han G, Zhang L and Yang B 2009 Mater. Chem. Phys. 113255 